\title{
EFEKTIVITAS LARUTAN MADU KELENGKENG (Euphoria longana Sp.) TERHADAP PEMUTIHAN GIGI (BLEACHING)
}

\author{
THE EFFECTIVENESS OF KELENGKENG HONEY (Euphoria longana Sp.) ON \\ BLEACHING
}

\author{
Ana Riolina, Aryant Dentia Rahmasari \\ Fakultas Kedokteran Gigi, Universitas Muhammadiyah Surakarta \\ Korespondensi: drg. Ana Riolina, MPH. Email: ana.riolina@ums.ac.id
}

\begin{abstract}
ABSTRAK
Bleaching adalah suatu cara yang digunakan untuk pemutihan gigi yang menggunakan bahan oksidator kuat. Oksidator yang biasa digunakan adalah hidrogen peroksida. Madu memiliki glucose oxidase yang berperan membentuk hidrogen peroksida saat madu dilarutkan dalam air. Kadar hidrogen peroksida dalam madu rata-rata $0,003 \%$. Tujuan penelitian ini untuk mengetahui efektivitas larutan madu kelengkeng (Euphoria longana Sp.) terhadap pemutihan gigi (bleaching). Penelitian ini merupakan penelitian eksperimental laboratoris dengan metode randomized pretest - postest controlled group design. Digunakan sampel 15 gigi premolar post ekstraksi. Pre-test dilakukan terlebih dahulu untuk mengukur warna gigi sebelum perlakuan. Larutan madu disiapkan dengan perbandingan 1:1 sebanyak $60 \mathrm{ml}$. Perlakuan pada sampel dilakukan selama 14 hari, setiap hari perendaman selama 3 jam dan setelah itu sampel direndam dalam saliva buatan. Pada hari ke 14 dilakukan pengukuran intensitas warna sebagai post-test. Hasil pengukuran diolah dengan dental digital photo CIE L*a*b* analysis. Hasil uji levene's test didapatkan hasil distribusi data normal $p=0,311(p>0,05)$, sehingga digunakan uji Independent T-test dan didapatkan hasil $\mathrm{p}=0,000(\mathrm{p}<0,05)$. Hasil ini menunjukkan bahwa terdapat efektivitas dari madu kelengkeng (Euphoria Longana $\mathrm{Sp}$ ) untuk pemutihan gigi.
\end{abstract}

Kata Kunci: Madu, Madu kelengkeng, Hidrogen peroksida, pemutihan gigi, warna gigi

\section{ABSTRACT}

Bleaching is a tooth whitening method using strong oxidizing material. Strong oxidizing material which is usually used is hydrogen peroxide. Honey has glucose oxidase which has role to form hydrogen peroxide when honey dissolved in water. The average levels of hydrogen peroxide in honey is about $0.003 \%$ on average.The purpose of this study is to known effectivity longan honey solution (Euphoria longana Sp.) in tooth whitening (bleaching). This was a laboratory experimental study with randomized pretest-posttest controlled group design method. Using a sample of 15 premolars post-extraction. Pre-test was performed to measure tooth color before treatment. Solution of honey is prepared with a ratio of 1:1 of 60ml. Treatment were taken for 14 days, soaking for 3 hours every day and then the samples soaked in artificial saliva. On $14^{\text {th }}$ day, the color intensity was measured as a post-test. The measurement results processed by the dental digital photo CIE $L^{*} a^{*} b^{*}$ analysis. Levene's test results showed normal data distribution $p=0.311$ ( $p>0.05$ ), so that the test used Independent T-tes and showed $p=0.000$ ( $p<0.05)$. These results indicating that there is effectivity for whitening tooth with longan honey (Euphoria Longana $\mathrm{Sp}$ ) solution.

Keywords: Honey, Longan honey, Hydrogen peroxide, tooth whitening, tooth color

\section{PENDAHULUAN}

Perubahan warna gigi dapat mengurangi keindahan penampilan dan rasa percaya diri. Hal ini mendorong adanya peningkatan akan kebutuhan perawatan gigi, terutama pemutihan gigi (bleaching) (Manuel et al, 2010).

Perubahan warna gigi ada dua yaitu perubahan warna ekstrinsik dan intrinsik. 
Perubahan warna intrinsik adalah perubahan warna pada gigi yang terjadi di dalam email dan dentin. Perubahan warna ekstrinsik ditemukan pada permukaan luar gigi, yang biasanya disebabkan oleh rokok, makanan dan minuman yang mengandung tanin, serta agen kation seperti chlorhexidine, atau garam mineral seperti besi. Warna gigi berhubungan erat dengan persebaran serta penyerapan cahaya oleh email, dentin dan pulpa karena tergantung pada ketebalannya. Dari ketiga bagian gigi diatas, dentin memiliki pengaruh yang besar terhadap warna alami gigi (Joiner, 2006).

Pemutihan gigi adalah proses pemutihan menggunakan bahan bersifat oksidator. Pemutihan gigi yang dikerjakan di klinik oleh dokter gigi menggunakan hidrogen peroksida dengan konsentrasi $30-35 \%$ sedangkan yang dilakukan oleh pasien sendiri atau pemutihan gigi di rumah menggunakan bahan karbamid peroksida $10-22 \%$, gel pemutih hidrogen peroksida berkonsentrasi 1,5\% yang cukup efektif memutihkan gigi. Selama ini hidrogen peroksida berasal dari bahan kimia dan apabila digunakan untuk gigi yang vital akan memberi efek yang merugikan yaitu membunuh pertumbuhan jaringan baru dan mengiritasi jaringan sehat sekitar gigi.

Efek samping penggunaan bahan kimia pemutih gigi antara lain gigi sensitif, iritasi gingiva, sakit tenggorokan, rasa perih pada rongga mulut dan reaksi alergi. Bila efek samping ditemukan pada seseorang yang sedang melakukan pemutihan gigi, maka proses tersebut harus dihentikan. Pengurangan efek samping untuk sensitifitas gigi setelah dilakukan pemutihan gigi dapat diberikan bahan desensitizing yaitu pottasium nitrate, fluor atau bahan yang mengandung air dan fluoride. Meningkatnya ion pottasium nitrate membuat kavitas pada tubulus dentin terlindungi sehingga rasa sensitif gigi dapat berkurang (Farahanny, 2009).

Madu adalah bahan alami yang sudah lama digunakan sebagai salah satu obat alternatif yang telah lama dipakai dan dikenal. Hidrogen peroksida $\left(\mathrm{H}_{2} \mathrm{O}_{2}\right)$ terdapat pada madu, kandungan hidrogen peroksida pada madu yaitu $0,003 \%$ pada tiap mililiter. $\mathrm{H}_{2} \mathrm{O}_{2}$ tersebut melalui radikal bebas reaktif dapat menghancurkan ikatan konjugasi pada molekul-molekul zat warna pada noda sehingga molekul tersebut menjadi lebih sedikit berpigmen dan menyebabkan efek pemutihan.
Hidrogen peroksida yang berada dalam madu berasal dari reaksi oksidasi glukosa, oksigen dan air serta memiliki hasil lain yaitu gluconic acid (Ahuja \& Ahuja, 2010). Kandungan hidrogen peroksida ini dapat terbentuk apabila madu dilarutkan dalam air. Reaksi yang terbentuk adalah:

$$
\mathrm{C}_{6} \mathrm{H}_{12} \mathrm{O}_{6}+\mathrm{H}_{2} \mathrm{O}+\mathrm{O}_{2} \rightarrow \mathrm{C}_{6} \mathrm{H}_{12} \mathrm{O}_{7}+\mathrm{H}_{2} \mathrm{O}_{2 .}{ }^{5}
$$

Hasil pelepasan hidrogen peroksida ini membuat madu memiliki daya antibakteri dan antijamur (Chen et al, 2012). Hidrogen peroksida inilah yang akan menjadi bahan pemutih gigi yang lebih alami dan aman. Atas dasar tersebut penulis ingin meneliti salah satu bahan alternatif alami untuk memutihkan gigi, yaitu madu dalam penelitian ini digunakan madu kelengkeng, dan apakah terdapat efekktivitas pada madu kelengkeng khususnya untuk memutihkan gigi / bleaching.

\section{METODE PENELITIAN}

Penelitian ini merupakan penelitian eksperimental laboratoris murni, yaitu kegiatan percobaan untuk mengetahui adanya pengaruh yang timbul sebagai akibat suatu perlakuan. Metode yang digunakan ialah randomized pretest - postest controlled group design, sehingga dapat diketahui kondisi sampel yang diteliti sebelum dan sesudah perlakuan dan hasilnya dapat dibedakan satu sama lain. Penelitian ini menggunakan sampel 15 gigi premolar post ekstraksi.

Seluruh sampel dibersihkan dengan air, lalu diberi tanda untuk membedakan kelompok satu dan lainnya serta diberi nomor urut, lalu dilakukan pengukuran intensitas warna pada seluruh sampel penelitian sebagai pre-test. Larutan madu disiapkan dengan melarutkan madu dan air dengan perbandingan 1:1 sebanyak $60 \mathrm{ml}$. Perlakuan pada sampel dilakukan selama 14 hari, setiap hari perendaman dalam larutan madu kelengkeng (Euphoria longana $S p$ ) dilakukan selama 3 jam, setelah 3 jam sampel gigi direndam dalam saliva buatan dengan membilasnya dengan air terlebuh dahulu. Pada hari ke 14 dilakukan pengukuran intensitas warna kembali sebagai post-test. Hasil pengukuran tersebbut diolah dengan metode dental digital photo CIE $L * a * b *$ analysis. 


\section{HASIL DAN PEMBAHASAN}

Berikut ini adalah data pengukuran perubahan warna pada tiap sampel sebelum dan sesudah dilakukan perlakuan perendaman dalam larutan madu. Hasil perhitungan CIE $L a b$ perendaman gigi dengan madu kelengkeng (Euphoria longana Sp)

\begin{tabular}{cccc}
\hline \multirow{2}{*}{ Sampel } & \multicolumn{3}{c}{ Nilai dE*ab } \\
& \multicolumn{3}{c}{ Larutan madu kelengkeng } \\
\cline { 2 - 4 } & Sebelum & Sesudah & Selisih \\
\hline 1 & 51,08 & 78,26 & 27,18 \\
2 & 74,97 & 85,49 & 10,51 \\
3 & 69,92 & 82,22 & 12,29 \\
4 & 64,50 & 83,41 & 18,90 \\
5 & 50,80 & 72,11 & 21,31 \\
6 & 55,09 & 63,10 & 8,01 \\
7 & 73,76 & 83,57 & 9,80 \\
8 & 69,40 & 81,51 & 12,11 \\
9 & 62,89 & 66,51 & 3,61 \\
10 & 71,87 & 79,58 & 7,71 \\
11 & 68,77 & 77,39 & 8,62 \\
12 & 65,82 & 70,96 & 5,13 \\
13 & 71,19 & 75,45 & 4,25 \\
14 & 57,31 & 73,36 & 16,04 \\
15 & 74,06 & 74,12 & 0,05 \\
\hline
\end{tabular}
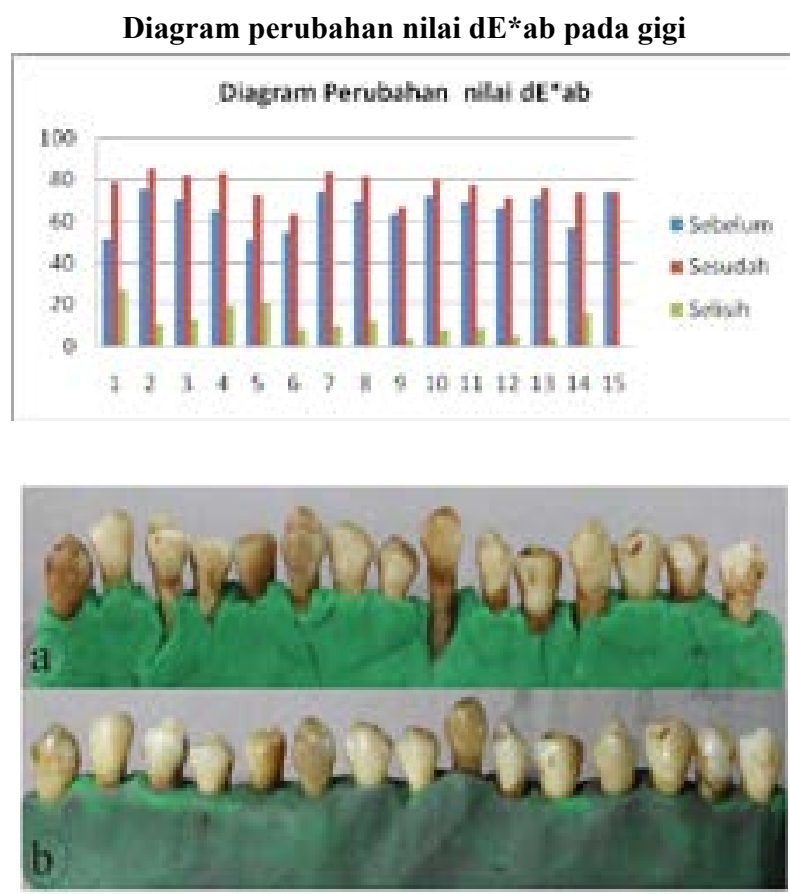

(a) vanoel givi sebvlume fircndem lanutas madu kelondene. (b) arrocl gigi sctelah dirndam larutan mada keknglene.
Hasil uji levene's test didapatkan hasil distribusi data pada larutan madu kelengkeng normal $\mathrm{p}=0,311(\mathrm{p}>0,05)$ dengan hasil tersebut, maka dilanjutkan uji statistik dengan uji independent $t$ - test dan didapatkan hasil $\mathrm{p}=0,000$ $(\mathrm{p}<0,05)$. Hasil ini menunjukkan bahwa Larutan madu kelengkeng (Euphoria longanna $\mathrm{Sp}$ ) terbukti dapat memutihkan gigi.

Penilaian warna gigi yang biasa dipakai di klinik oleh dokter gigi dengan teknik visual, yaitu dengan menggunakan shade guide. Hasil dari penilaian warna gigi dengan teknil visual ini subjektif karena dipengaruhi oleh banyak faktor, seperti cahaya, umur, kelelahan mata pemeriksa (Sikri, 2010). Teknik instrumental dalam penilaian warna gigi memiliki banyak keunggulan daripada teknik visual. Sensor kamera DSLR yang digunakan sebagai pengganti spectrophotometer dan colorimeter yang lebih sensitif dan peka terhadap warna membuat nilai $\mathrm{dE}^{*} \mathrm{ab}$ yang dihasilkan lebih akurat. Pada prinsipnya, penilaian dengan specrophotometer hampir sama dengan prinsip dental digital photo CIE $L^{*} a^{*} b^{*}$ analysis ( Sluzker et al, 2011), sehingga dalam penelitian ini digunakan kamera DSLR dan adobe software untuk melakukan penilaian warna gigi.

Pengambilan gambar dilakukan pada siang hari, di Laboratorium FKG UMS dengan latar belakang kartu abu - abu $18 \%$, sudut pengambilan gambar $60^{\circ}$, lampu ruangan yang cukup dan kamera yang diletakkan pada tripod dengan pengaturan shutter speed $1 / 15$, bukaan f-16, iso 6400 dan lensa $55 \mathrm{~mm}$. Jarak pengambilan gambar minimal yaitu 1:2 atau $3: 4$ antara tinggi kamera dan jarak dari gigi ke tripod (Bengel, 2006).

Hasil foto dianalisa dengan metode dental digital photo analysis CIE $L^{*} a * b^{*}$ menggunakan adobe software dengan mode Lab color akan didapatkan nilai $\mathrm{L}$, $\mathrm{a}$, dan $\mathrm{b}$ pada tiap gigi yang diukur kecerahannya lalu kita masukkan dalam rumus sebagai berikut :

$$
\Delta \mathrm{E}_{\mathrm{ab}}^{*}=\left(\Delta \mathrm{L}^{* 2}+\Delta \mathrm{a}^{* 2}+\Delta \mathrm{b}^{* 2}\right)^{1 / 2}
$$

Dari hasil sebelum dan sesudah perendaman terlihat bahwa nilai $\mathrm{dE}^{*} \mathrm{ab}$ meningkat, hal ini membuktikan bila nilai $\mathrm{dE}^{*}$ ab yang semakin tinggi maka gigi tersebut semakin putih (Benbachir et al, 2008). Hasil hidrogen peroksida yang terbentuk didapat dari gula madu yang terolah mengandung 
enzim glucose oxidase yang ada dalam perut lebah, sehingga hidrogen peroksida yang terbentuk pada gula, hanya dihasilkan oleh madu yang dihasilkan oleh lebah. Glucose oxidase sangat berperan penting dalam pembentukan hidrogen peroksida dalam madu,sehingga perubahan glukosa menjadi asam glukonat dan hidrogen peroksida dapat terbentuk (Ahuja \& Ahuja, 2010).

Dalam proses pemutihan gigi, reaksi pemutihan gigi yang terjadi adalah reaksi oksidasi karena hidrogen peroksida merupakan oksidator kuat. Proses pemutihan gigi dimulai dari tubuli dentinalis melalui email, lalu reaksi oksidasi akan terjadi dengan senyawa kimia yang menumpuk dan membuat warna gigi gelap, senyawa tersebut dirusak oleh reaksi oksidasi yang dilakukan hidrogen peroksida dengan memutus ikatan rangkap dalam ikatan konjugasi pada molekul zat warna (Joiner, 2006).

Reaksi ini akan menurunkan molekul dengan pigmen tinggi menjadi molekul dengan pigmen rendah, dalam hal ini dari warna yang gelap menjadi putih. Turunnya pigmen ini membuat permukaan gigi akan semakin terang dan semakin mudah untuk merefleksikan warna gigi dan membuat kesan gigi menjadi leb ih putih dari sebelumnya (Joiner, 2006).

\section{SIMPULAN}

Penelitian ini membuktikan bahwa dengan kadar hidrogen peroksida yang relatif kecil pada larutan kelengkeng (Euphoria longana $S p$ ) dapat memiliki efek yang berarti untuk memutihkan gigi. Waktu penggunaan madu untuk memutihkan gigi juga dapat ditoleransi tubuh, karena pada dasarnya putihnya gigi saat konsumsi larutan madu merupakan efek samping baik yang bisa didapatkan, namun bila larutan madu digunakan langsung untuk memutihkan gigi, hasil yang didapat membutuhkan waktu yang lebih lama dibanding hidrogen peroksida dengan kadar tinggi.

\section{DAFTAR PUSTAKA}

Ahuja A. dan Ahuja V., 2010, Apitherapy - A Sweet Approach to Dental Diseases - Part I : Honey, Journal of Advanced Dental Research, I : 81-86.

Benbachir, N., Ardu, S., Krejci, I., 2008, Spectrophotometric Evaluation of The Efficacy of A New InOffice Bleaching Technique, Quintessence International, 39 (4) : 299-306.

Bengel W. 2006. Matering Digital Dental Photography. Berlin: Quintessence.

Chen C., Leona T. C., Shona E. Blair, dan Dee A.C., 2012, The Effect of Standard Heat and Filtration Procesing Procedures on Antimicrobial Activity and Hydrogen Peroxide Levels in Honey, Journal of Microbiology, University of sydney.,University of New South Wales, Australia.

Farahanny W., 2009, Efek Samping Office Bleaching dan Home Bleaching Terhadap Gigi, Tesis, Sumatera Utara : Departemen Ilmu Konservasi, Fakultas Kedokteran Gigi, Universitas Sumatera Utara.

Joiner A., 2006, The Bleaching of Teeth : A Review of The Literatur, Journal of Dentistry, 34 :412-419.

Sikri V.K., 2010, Color : Implications in Dentistry, Journal of Conservative Dentistry, 13 (4) : 249-255.

Sluzker A., Knosel, M., Doc, Priv., E, Athanasiou., 2011, Sensitivity of Digital Dental Photo CIE L*a* $b^{*}$ Analysis Compared To Spectrophotometer Clinical Assessments Over 6 Months, American Journal of Dentistry, 24 (5) : 300-304.

Manuel S.T., Abhisek P., dan Kundabala M., 2010, Etiology of Tooth Discoloration - A Review, Nig Dental Journal, 18 (2) : 56-63. 